\title{
"To Vaccinate or not to Vaccinate my Child?" What Is at Stake in Vaccination Repertoires?
}

\author{
Cosmin Toth (University of Bucharest)
}

\begin{abstract}
:
One of the most hotly debated topics in Romania in recent years has been the vaccination of children, especially in relation to the measles epidemic that began in 2016 and continues to this day. Using a discourse analytic perspective, this article addresses the main interpretative repertoires regarding the vaccination of children displayed in interview situations by two categories of parents, namely those who decided to vaccinate their children and those who refused to vaccinate their children. Regarding the first group, I have identified the following repertoires: (1) the repertoire of "I trust doctors, I trust science" as a repertoire of expressing total trust; (2) the repertoire of hypocrisy and ridicule in relation to "vaccine refusers" and (3) the repertoire of the absurdity of anti-vaccine theories. These repertoires come together into a broader discursive framework of epistemic superiority. The second group of parents (those who decided to refuse vaccination) developed a series of sub-repertoires to substantiate a rational, responsible and loving parent's identity. I conclude that although we are witnessing a dynamic dialogic construction, at present the repertoires are constructed in a way that cancels out a possible dialogue between the two groups. On the one hand, those who support vaccination do so from a position of epistemic superiority, accusing vaccine refusers of lack of reason and education. On the other hand, those who refuse vaccination construct hypertrophied and complex repertoires of responsibility, rationality and affectivity meant to replace the legitimacy of scientific, medical and administrative institutions as a basis for parental decision making.
\end{abstract}

Keywords:

discourse analysis; interpretative repertoires; Romania; vaccination

Measles is a vaccine-preventable, contagious disease that has given rise to heated debates in the Romanian media. This is not surprising given that Romania has faced several waves of measles outbreaks since 2016. In November 2019, the National Institute of Public Health Romania (NIPHR) reported 20192 cases of measles in Romania since January 2016 and 64 deaths. Even the World Health Organization and UNICEF reported that measles cases are currently at the highest level that they have been in any year since 2006 (World Health Organization, 2019). The latest NIPHR report (2019) estimates a measles vaccine coverage of $92.2 \%$ for the first dose of the vaccine, with a rate that has been declining as of $2010(95 \%)$, but slightly increasing compared to 2017 and 2018. Beyond issues such as availability and healthcare service access, vaccination refusal has recently become an important cause of low vaccination rates. NIPHR reports that at the end of 2019, those refusing to have any type of vaccine, account for around $9.4 \%$, while for measles the figure is $11.8 \%$, relative to the total number of unvaccinated children.

Given the high number of measles cases, vaccines and vaccination have become a matter of public debate both in the broadcasting media (press and television) and digital media (Internet). Here specific rhetorics have begun to emerge either opposing or supporting vaccination. Nonetheless, beyond the active promoters of the antivaccination movement or their opponents, are the parents who have to make a decision about immunizing their children. They are the recipients, but also the contributors to, and sometimes the promoters of these rhetorics. These rhetorics in turn forms part of shared discursive resources that are employed to shape, support and justify decisions of vaccine rejection, postponement or acceptance. The theoretical and methodological approach of this paper, namely discourse analysis, aims to analyse these rhetorics, considered as playing an important role in parents' decisions. Discourse analysis starts from several premises that emphasize the importance of language as a significant factor in understanding human action. Thus, discourse analysis is "the study of language-in-use" (Gee, 2011, p. 8). According to this approach, discourse is not only a means of conveying information, but is the primary arena for human action, understanding and intersubjectivity (Potter, 2012, p. 4). Analysis is focused on the functions of language, on what language does (Potter \& Wetherell, 1987), because language allows us not only to say things but also to do things and to be things (Gee, 2011). Moreover, discourses are always political insofar as they have implications for the wider 
public, they are responsible for building things, carrying out ideological work and are meant to legitimize certain positions (Fairclough et al., 1997; Gee, 2011; Van Dijk, 2015, p. 467).

According to Wetherell and Potter (1988), interpretive repertoires are the building blocks of discourse analysis. Repertoires represent a cluster of terms, categories and idioms that are closely and conceptually organized (Potter, 2012), constituting a "restricted range of terms used in a specific stylistic and grammatical fashion" (Wetherell \& Potter, 1988, p. 172). The aim of this material is to provide an insight into the main interpretative repertoires used by two Romanian categories of parents, namely those who decided to vaccinate their child/children and those who refused vaccination. These repertoires are treated here as resources that are available and circulated across a market of competitive discourses in order to shape, support and justify decisions. A second objective is to provide a description for the functions that these repertoires fulfil.

The following analysis is based on 10 interviews that I have conducted as part of a larger study of discourses relating to vaccination among Romanian parents. Here, I specifically draw on these 10 qualitative interviews, five with parents who decided not to vaccinate at least one of their children and five with parents who stated that they had vaccinated all their children. In the following, I will refer to the former category as 'vaccine refusers' and not as 'anti-vaccinists' because the selection criterion was the decision and not the position on the vaccine. By the general category 'anti-vaccinists' I mean a publicly declared and consistent discursive position against vaccination.

I selected participants based on personal recommendations and only included parents of children of 10 years old or younger, all residing in urban areas and having obtained a higher education degree. The declared aim of the interview was to collect opinions on vaccines and vaccinations. The general strategy during the meeting was that of minimal intervention on the part of the interviewer, who suggested some general topics for discussion, then allowed the interviewees to express their opinions and positions as far as possible. The interviewer introduced himself as a researcher investigating the pros and cons of vaccination.

\section{Repertoires of Parents Who Decided to Vaccinate Their Child/Children}

I will begin by presenting the three main repertoires identified in the interviews with parents who stated that they had vaccinated their children: (1) the repertoire of "I trust doctors, I trust science" as a repertoire of expressing total trust; (2) the repertoire of hypocrisy and ridicule in relation to "vaccine refusers" and (3) the repertoire of the absurdity of anti-vaccine theories. These repertoires come together into a broader discursive framework of epistemic superiority. Below I will analyse certain brief examples from the interviews to illustrate this argument. These excerpts are not representative of an entire population, but the repetitiveness and similar patterns of construction across interviews, may be regarded as indicators of repertoires that are commonly used in daily interactions and, through constant refinement, may become rhetorical weapons. Anti-vaccine repertoires seem to respond to these repertoires, thus demonstrating their validity and functionality.

The first repertoire identified is that of full confidence in medicine, doctors and vaccines. In general, this positioning is built in explicit contrast to the anti-vaccine movement. Although the purpose of the discussion was not related specifically to anti-vaccinists, but opinions about vaccines in general, the respondents spontaneously built a discursive position of opposition to the anti-vaccine movement.

The excerpt below exemplifies this repertoire.

(1) I position myself within the group which has absolute trust in the vaccines.

(2) I mean no...I have no doubts about the composition of vaccines...

(3) I didn't even stop to analyse the composition of the vaccine and where it comes from...

(4) I really trust the doctor who recommended them to me and who gave my children the vaccine.

From the outset, in line (1), the interviewee is constructing membership categories (Saks, 1992) and places himself in the category of the trustees, namely those who have absolute confidence in the vaccine. What is made relevant here is a thus making relevant the division of the world into those who trust, and hence occupy a legitimate positioning vis-a-vis vaccination, and those who do not. Through this construction, the hypertrophied assertion of trust becomes more intelligible and acceptable. Trust becomes so great that information is no longer needed, and distrust is regarded as a rather reprehensible trait of the group of 'others' (anti-vaccinists). Finally, in line (4), the interviewee reaffirms the trust not only in the vaccine but also in the doctors.

This construction simultaneously manages to discursively build the pro- and anti-vaccine categories together with the properties and traits of their members, those in the pro-vaccine camp having an absolute trust in the vaccine and the doctors, without the need for information, and those harbouring a feeling of distrust.

In the following paragraphs, I will present two different interviews, which do the same discursive work of defining the categories and the properties of the pro- and anti-vaccine camps respectively. Thus, in the first paragraph, a dialogue is set out in narrative form, indexing the existence of those who are hesitant about vaccination, in an attempt to reaffirm the agreement to carry out the vaccination. Line 2 shows the 'properties' of the members of the two sides:

(1) Some acquaintances come to ask me... are you sure 
the vaccination is safe? Yes, it is safe.

(2) I mean, I trust doctors, I trust science but I don't trust the views of certain pseudo-doctors from google searches.

In the above excerpt, the interviewee signals his/her position of confidence regarding the vaccines' safety in contrast to others who are unsure. In addition, he/she justifies this trust not from his/her own corpus of information, but by the questionable quality of information obtained from "google".

The same dichotomy is emphasized in the next excerpt which constructs the difference between a group of mothers who obtain information from the Internet and those who go to the doctor in case of a medical concern. This construction process begins from line 1, along with the positioning of the interviewee on the side of those who do not get their information from the Internet. Line 2 also specifies the source of information for those who do not inform themselves from the Internet, namely "Mother and Child" (Mama şi Copilul) - a Romanian book that has traditionally been considered for many decades as the main paediatric guide for new mothers. Line 3 even presents a model of good practice that condemns those who seek advice on the Internet when they have a problem, distinguishing them from those who go to the doctor.

(1) I am not part of the group of mothers who obtain information from the Internet.

(2) On the contrary, I read the book "Mother and Child", I have a family doctor with whom I consult, whom I trust and with whom I have a very good relationship.

(3) If my children are ill, I do not immediately go online to ask a forum of mothers. I take my children to the doctor, if I have a real concern.

A rhetoric of discursively hypertrophied trust in the medical system is displayed in the examples presented so far, but also a construction of two opposing membership categories: those who trust doctors and those who are distrustful, insecure and reprehensibly informed by the Internet.

In the following section, I will present a set of discourses that indicate in another form the display of an epistemic superiority of the "pro-vaccinists". This type of approach has already been expressed regarding the sources of information of the anti-vaccinists (Internet). The following ways of expressing the relationship of superiority and inferiority point to rhetorical strategies such as sarcasm, framing vaccine refusers as hypocrites.

The first rhetorical strategy used is sarcasm in relation to the anti-vaccinists' understanding of medicine. The tone is condescending:

(1) Actually, an acquaintance who has not vaccinated his children advises me:
(2) ahhh, it hurts, you have stomach problems, take some essential oils.

(3) I say ok, I can use essential oils but it won't take my pain away.

A generic dialogue with an acquaintance who has not vaccinated his children is used as an introductory pretext (line 1). In this way he gives consistency and authenticity to the narrative and to the claims of those who do not vaccinate their children. Line 2 states the recommendation of the "acquaintance", then (in line 3), the interviewee intervenes with a sarcastic response that demonstrates the absurdity of this recommendation. Thus, in this excerpt, the interviewee manages to create a category, giving it authenticity and positioning himself as superior to it.

A second strategy of projecting a sense of epistemic superiority is highlighting inconsistencies in the other camp's arguments. In the example below, the interviewee describes a mismatch between the theories and the actual behaviour of vaccine refusers in relation to a common theme (i.e., the heavy metal content of vaccines):

(1) There are foods that you eat every day, that you use every day, that contain all these substances, so I don't see why you wouldn't take a vaccine once and...

(2) So... people believe that the fish in the oceans are full of mercury.

(3) Now I would ask someone who hold such ideas, when they last ate fish.

The interviewee aims to invalidate one of the reasons used most frequently by vaccination opponents for vaccination refusal. By evoking an imaginary dialogue with a real person, this discursive construction also becomes an accusation of hypocrisy, a rhetorical attack against a particular category and not just a simple indication of an inconsistency between theory and practice.

Finally, let us consider a series of repertoires through which the practices and theories of vaccine are constructed as absurd, irrational and unfounded. Anti-vaccine theories are delegitimized, especially those related to the association between vaccines and autism, being labelled as absurd and based on rumours or chimeras.

In the excerpt below, anti-vaccine theories and information are disproved by emphasizing the lack of scientific evidence. This time the rhetorical strategy simply constitutes labelling and analogy, the information being treated as rumours, circulated only in informal discussions. In this way, any claim to the validity of the information is denounced, without too much argumentation and/or problematization.

These ideas are at the level of rumours, you discuss things like this at the market, and unfortunately too many people believe these things. 
In the next example, however, the discursive construction is broader, the tone being more aggressive and superior, because it is personalized by using the second person, singular form pronoun. The discourse is enacted as an imaginary dialogue between the interviewee and a generic person that the interviewee admonishes. The excerpt also starts by discrediting the relationship between vaccines and autism as absurd. In addition, the admonition is further elaborated by delegitimizing the claim that the anti-vaccinists are well informed.

(1) It is absurd to claim that a child who is vaccinated today will have autism tomorrow,

(2) that is, your level of information...although you say that you have read about the subject and you are superinformed, it seems to me that you have a limited amount [of information] if you can say something like...'autism has developed overnight', when it is clear that this happens over time...

The repertoire mobilized here is that of delegitimizing anti-vaccine theories against a background of a lack of documentation and information, suggesting - as in the other cases presented here - a position of epistemic superiority. The interviewee constructs a simplified discursive image of the vaccine refusers, who are depicted as absurd, hypocritical and uninformed, in contrast to his/her own image of unconditional trust in vaccines, medicine and doctors.

\section{Repertoires of Parents Who Decided Not to Vaccinate Their Child/Children}

In contrast to the discourses of pro-vaccine parents, the discursive constructions of parents who decided against vaccination seem to be directly related to the aforementioned repertoires, thus entering into an (imaginary) dialogue with them. While parents who vaccinated their children construct accusatory discourses against anti-vaccinists from positions of epistemic superiority, parents who did not vaccinate their children used constructions that served to legitimize an identity of the rational, informed, loving and responsible parent. In a previous study (Toth, 2019) I revealed some of the most significant identity claims displayed by parents who decided not to vaccinate their children. The main discursive constituents of these contextualized identity constructions were categorized as sub-repertoires, all serving as a discourse relating to parental responsibility, rationality and love. The following such sub-repertoires were identified (Toth, 2019):

- The transition from the ignorant and credulous parent to the knowing parent: "Before, I was naive...but now I know". Through this subrepertoire, parents describe a process of passing from the naive to the informed parent, thus proving that they are more informed than others and thus more responsible.

- The responsible and loving parent: "I am a loving and responsible parent just like all parents are".
Here we encounter a discursive tendency of claiming to belong to a category of "normal" parents, who are loving and responsible. The discursive markers of this sub-repertoire are based on the reaffirmation that the parents themselves know best for their own child. In this way, the indisputable right to decide is also recovered

- The balanced medical decisions: "I will take him to the hospital if required". Within this sub-repertoire, the ability to make a balanced decision is discursively reaffirmed, thus constructing the identity of a rational, balanced and responsible parent. In this type of intervention, respondents reject the extreme alternatives of medical decisions that oppose the classic procedures of allopathic medicine.

- The proper documentation: "I go to the source, I don't rely on the Internet". This is an important subrepertoire, which appears to be a direct response to public negativity towards anti-vaccinists. Here the interviewees emphasize the quality of the information sources, while rejecting the Internet as being such a source. This sub-repertoire depicts the process of gathering information as being substantial and consistent and deriving from legitimate sources. The scientific titles of the authors and the fact that they "go to the [primary] source" are often invoked in a hypertrophied manner.

- The disclaimer of anti-vaccine militancy: "I am not trying to convince anyone". This is probably one of the most important rationalizing sub-repertoires, in which the right to decide is built by affirming a tolerant and balanced position. This sub-repertoire constructs both a balanced position and a claim to the right to decide, by demonstrating one's own tolerance and thus an invitation to reciprocity.

- The rejecting of any risk out of love: "I will not risk the love of my life". The last sub-repertoire identified is one of justification, of rejection of the risks on the basis of parental love who refuses the exposure of a child to any risk. However, the risk to which these parents relate, is the risk associated with the vaccination of their own child and not the risks of vaccine-preventable diseases. This repertoire, together with that of the responsible and loving parent, who claims to know what is best for his/her own child, contributes significantly to the construction of the loving and responsible parent.

In summary, although the sub-repertoires mentioned are interrelated and have developed in response to one another, they seem to operate independently, given that the interviews were conducted within a relatively short time period (two months). If we are to use the metaphor of a dialogue, it is 
obvious that we are not dealing with a direct form of dialogue, aimed at finding and establishing a scientific truth, but rather a series of inter-related discursive constructions to impose the legitimacy of one's own position. In other words, there is no dialogue to find a common solution, but rather a conflicting win-lose situation, in which the imposition of one's own position is carried out by weakening and delegitimizing the opposing position. I am mentioning "dialogue" because the identified discourses seem, in fact, to have been developed over time as a dialogic repertoire, by means of a historical process of statement-accusationresponse. The understanding of this process of discursive construction as a dialogue of repertoires, is suggested by the construction of discourses themselves and the discursive hypertrophy of certain positionings and identities. Thus, on the one hand, we have the discourses of the pro-vaccinists as having absolute confidence in the medical system, doctors and science, and the hypostasis of the vaccine refusers as absurd, hypocritical and undocumented. On the other hand, we have the repertoires of the vaccine refusers that put effort into displaying an identity of themselves as rational, balanced, loving and responsible parents (Toth, 2019). Thus, pro-vaccinists continue unabated to adopt a position of epistemic superiority, accusing the parents who do not vaccinate their children of irrationality, despite the vaccine refusers efforts to prove otherwise. On the other hand, parents who have decided not to vaccinate their children do not seem to account for the risks of vaccination/non-vaccination, investing more effort in demonstrating post-factum the rationality and responsibility of their position, thus claiming the right to decide and reclaiming their status as parents who know what is best for their own child.

What ultimately emerges from the analysis of these repertoires is the erroneous consideration of the fact that those who refuse vaccination do so because they are not educated and uninformed, a situation contradicted by the vaccine refusers' high level of education and also the volume of information and arguments discursively displayed by them. This lack of convergence not only favours an increase of the social cleavage, but also the crystallization of separate and separating repertoires. The consequence is the cancellation of a potential dialogue to correct and adapt decisions to scientific and medical realities. In addition, this state of affairs may produce and amplify repertoires of dislocation and the decline of the legitimacy of structures established by governmental and scientific authorities, not only at the level of the promoters of the anti-vaccine movement but also among ordinary parents that have to make a decision. Thus, the validation, through the lack of adequate reaction and the development of scientific and moral assumptions by anti-vaccinists, paves the way for the legitimization of an alternative scientific vision, while discrediting the capacity and good intentions of government institutions and the scientific basis of medicine. The identity construction of parents who refuse vaccination precisely because they are in fact responsible, loving, rational and informed, and are able to deliver increasingly refined scientific references and medical theories, develop into circulating repertoires at the disposal of any parent who needs to make a decision about his/her child's immunization.

\section{References}

Fairclough, N., Mulderrig, J., \& Wodak, R. (1997). Critical discourse analysis. In T. van Dijk, (Ed.), Discourse studies: A multidisciplinary introduction (2nd ed., pp. 357-378). Sage.

Gee, J. P. (2011). An introduction to discourse analysis: Theory and method (3rd ed.). Routledge.

National Institute of Public Health Romania. (2019). Analiza evoluției bolilor transmisibile aflate în supraveghere: Raport pentru anul 2018. https://www.cnscbt.ro/index.php/rapoarte-anuale/1302-analiza-bolilor-transmisibile-aflate-insupraveghere-raport-pentru-anul-2018/file

Potter, J. (2012). Discourse analysis and discursive psychology. In H. Cooper et al. (Eds.), APA handbook of research methods in psychology (pp. 119-138). American Psychological Association Press.

Potter, J., \& Wetherell, M. (1987). Discourse and social psychology: Beyond attitudes and behaviour. Sage Publications.

Sacks, H. (1992). Lectures on conversation (G. Jefferson, Ed.; Vol. 1-2). Blackwell. https://doi.org/10.1002/9781444328301

Toth, C. (2019). The rational, loving and responsible parent. A discursive construction of the identities of the parents that decided not to vaccinate their children. Journal of Comparative Research in Anthropology and Sociology, 10(2), 114. https://doi.org/10.6084/m9.figshare.12060480

Van Dijk, T. (2015). Critical discourse analysis. In D. Tannen, H. Hamilton, \& D. Schiffrin, (Eds.), The handbook of discourse analysis (2nd ed., pp. 466-485). Wiley.

Wetherell, M., \& Potter, J. (1988). Discourse analysis and the identification of interpretative repertoires. In C. Antaki (Ed.), Analysing everyday explanation. A casebook of methods (pp. 168-183). Sage. 
World Health Organization. (2019). New measles surveillance data from WHO: provisional data based on monthly reports to WHO (Geneva) as of August 2019. https://www.who.int/immunization/newsroom/new-measles-data-august-2019/en/

\title{
Recommended Citation
}

Toth, C. (2020). "To vaccinate or not to vaccinate my child?" What is at stake in vaccination repertoires? On Education. Journal for Research and Debate, 3(8). https://doi.org/10.17899/on_ed.2020.8.8

\begin{abstract}
About the Author
Cosmin Toth is lecturer at the Faculty of Sociology and Social Work, University of Bucharest. Currently, he is interested in Discourse Analysis (DA) approaches to understanding the multiple and intricate ways in which language is used for constructing and shaping identities and social realities. His most recent paper, The rational, loving and responsible parent. $A$ discursive construction of the identities of the parents that decided not to vaccinate their children (2019) focuses on interpretative repertoires as discourse resources for making decisions and constructing identities.
\end{abstract}

\section{Acknowledgements}

This work was supported by a grant from the Ministry of Research and Innovation, CNCS - UEFISCDI, grant no.89/2018, PNIII-P1-1.1-PD-2016-0145, within PNCDI III. 